\title{
Mental health needs for children of parents seeking help for substance abuse
}

\author{
Anne E. Thompson and Richard Blennerhassett
}

\begin{abstract}
A survey of 101 now attenders at a regional drug and alcohol service found that 46 adults had a total of 88 children at home. Twenty-three children were considered by their carers to show signs of emotional or behavioural disturbance. Dificulties had only been discussed with professionals in a minortly of cases. Help for troubled children from primary care services was preferred to secondary services. Closer liaison between child psychiatiy and primary health care workers should be considered.
\end{abstract}

Children of parents who have drug and alcohol problems are at an increased risk of psychiatric disorder both in childhood (Von Knorring, 1991) and in adult life (Mathew et al, 1993). The number of children therefore potentially benefiting from mental health services may be vast (MacDonald \& Blume, 1986).

Research programmes in the United States which have attempted to identify and help school children whose parents abuse substances have had problems recruiting children (Emshoff \& Anyan, 1991). In the United Kingdom, individual children whose parents have alcohol or drug problems may come to the attention of child psychiatry services, but there are no coordinated services for identification or intervention.

In order to plan effective mental health services for these children, information is needed about how best to access children at risk, whether parents perceive a need for help with their children, and what type of service these parents would use when seeking advice about children's emotional or behavioural difficulties.

One group of children who might be particularly accessible to mental health professionals are those whose parents are already seeking professional help on their own behalf at drug and alcohol services. This may be an important subgroup of children because there is some evidence that they are especially in need of psychiatric help (Heller et al, 1982).

The Northern Regional Alcohol and Drug Service (NORADS) has worked closely with the child and adolescent psychiatry service since 1992 in the development of services for adolescents with substance misuse (Blennerhassett et al, 1994). The following study was undertaken to assess whether child psychiatry might also have a role to play in the assessment of adult attenders at NORADS with children.

We aimed to determine how many children were in the care of adults who attended NORADS for assessment; whether there was any perceived disturbance in these children; to what extent parents believed their own problems had affected their children; parents' preferred means of seeking help for their children; and the degree to which professional support for these children was already in place.

\section{The study}

Adults who attended initial assessment sessions at NORADS over a six month period were asked to complete an anonymous 12 item questionnaire.

Data were collected about the number and ages of children at home; the nature of adults' relationship to the children: and help sought for the children in the previous three months and reasons for this; adults' perception of the extent to which children at home were affected by adult mental health problems; where adults would get help if they were worried about their children; and any potential difficulties in seeking help.

Data collected about the adults themselves included gender, age, the nature of their problems, and the source of their referral to the clinic.

\section{Findings}

A total of 101 new patients completed questionnaires representing $64 \%$ of all first attenders. The sample comprised 75 men and 26 women. This male-to-female ratio was similar to that of the total new patient population. Seventy per cent of adults were aged between 26 and 45 . Fifty-six per cent described themselves as having an alcohol related problem, $28 \%$ a drug related problem and $16 \%$ problems with both drug and alcohol use. 
Although the service is a regional referral centre, $74 \%$ of the sample had either referred themselves or been referred by general practitioners.

Forty-six of the adults had children in their care (37\% men and $69 \%$ women). There was no difference in the proportions of presenting problems between adults with or without children. Thirty-six $(78 \%)$ adults were parents of the children in their care; four were step-parents, four were brothers, one was a grandparent and one was unrelated to the child at home.

This sample of clinic attenders had 88 children at home. Of these children, $19(22 \%)$ were preschool children, $36(41 \%)$ were aged 6-10 and 33 (37\%) were aged 11-18. Twenty-three children $(26 \%)$ were judged by adults to have been upset or exhibiting difficult behaviour in the previous three months. Two-thirds of this disturbance was confined within the home. Ten children had received help and four had received help from more than one agency.

The majority of adults with children at home said that they would turn to family, friends, school staff or primary care workers for help if their children were upset or behaving badly. Six respondents said that fears about statutory agencies removing the children or embarrassment about admitting to problems with family life would prevent them from seeking help for their children at home.

Twenty-eight (61\%) adults with children at home felt that their substance misuse affected their children in some way. The most frequent explanation offered for this was that children had witnessed parental behaviours resulting from substance misuse such as intoxication, aggression or arguments. A second suggestion from adults was that children in their households sometimes suffered from lack of parental care or attention.

\section{Comments}

The level of psychological disturbance in children in the care of adults seeking help for drug and alcohol problems, as suggested by parental selfreport, is at the upper range of rates of psychological disturbance in the general population (Verhulst \& Koot, 1992). As parents underestimate the extent of internalising disorders in their children (Barrett et al, 1991) the true rate of psychiatric disorder in these children may be higher.

In spite of the regional function of this alcohol and drug service, the high numbers of primary and secondary referrals suggests that our findings may be typical of adults with drug and alcohol problems seen in primary care or nonspecialist psychiatric services.
The majority of adults surveyed recognised that their own substance misuse affected their children at home. However, less than half of the potentially disturbed children were receiving professional help. Intervention for these children would appear to be most acceptable to their families when it is available from community resources.

\section{Conclusions and implications for professionals}

Mental health workers in drug and alcohol services should be aware that there are considerable numbers of children in the care of their clients. Parental reports indicate that there may be substantial psychiatric morbidity among these children.

School staff, health visitors and general practitioners need to be aware of the potential for disturbance in children from households where adults have alcohol or drug problems: they are the professionals most likely to be approached by worried parents.

This study does not lend support to the development of a specialist role for child psychiatry in the assessment of adult substance misusers with children, but does suggest a need for closer liaison with primary care workers to meet the needs of this vulnerable group of children.

\section{Acknowledgements}

We thank Drs Eilish Gilvarry and Paul McArdle for their help with this study.

\section{References}

BARRETt, M. L., BERNEY, T. P.. BHATE, S., et al (1991) Diagnosing childhood depression. Who should be interviewed - parent or child? The Newcastle Child Depression Project. British Journal of Psychiatry. 160 (Suppl. 11), 22-27.

Blennerhassett, R., GIlvarRy, E. \& Tayler, P. (1994) A substance misuse clinic for adolescents. Psychiatric Bulletin, 18, 401-402.

EMSHOFF, J. G. \& ANYAN, L. L. (1991) From prevention to treatment: issues for school aged children of alcoholics. In Recent Developments in Alcoholism. Vol. 9 (ed. M. Galanter), pp. 327-346. New York: Plenum Press.

Heller, K., Sher, K. J. \& Benson, C. S. (1982) Problems associated with risk overprediction in studies of offspring of alcoholics: implications for prevention. Clinical Psychology Review, 2, 183-200.

MACDONALD, D. R. \& BUUME, S. B. (1986) Children of alcoholics. American Joumal of Diseases of Children. 140, 750-754.

MATHEW, R. J., Wilson, W. H., BlAZER, D. G., et al (1993) Psychiatric disorders in adult children of alcoholics: data from the epidemiologic catchment area project. American Joumal of Psychiatry. 160, 793-800. 
VERHULST, F. C. \& KoOT, H. M. (1992) Child Psychiatric Epidemiology: Concepts, Methods and Findings (pp. 128130). Newbury Park: Sage.

VON KNORRING, A. (1991) Annotation: children of alcoholics. Journal of Child Psychology and Psychiatry. 32. 411-421.

*Anne E. Thompson, Senior Registrar in Child Psychiatry. Fleming Nuffield Unit for Children and Young People, Burdon Terrace, Jesmond,
Newcastle upon Tyne, NE2 3AE; and Richard Blennerhassett, Consultant in General Adult Psychiatry, formerly Senior Registrar in Psychiatry, Northern Regional Alcohol and Drug Service, Plummer Court, Carliol Place, Newcastle upon Tyne, NE1 6UR

*Correspondence

\section{So Young, So Sad, So Listen}

\section{By Philip Graham \& Carol Hughes}

Depression is one of the most common, serious problems in today's school-age population. However, it is only relatively recently, in the past 20 years or so, that it has become clear that a significant number of children and teenagers have such serious disturbances of mood that it is quite appropriate to think of them as having depressive disorders.

This book is about depression in children and teenagers during their school years, from 5 to 16. It tries to explain ways that depression can be recognised by parents, teachers and the young themselves and explains what can be done to help.

\section{$\bullet £ 5.00 \bullet 56 p p . \bullet 1995 \bullet$ ISBN $090224180 \mathrm{X}$}

Available from bookshops and from the Publications Department, Royal College of Psychiatrists, 17 Belgrave Square, London SW1X 8PG (Tel. 0171-235 2351 extension 146)

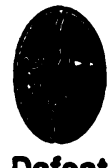

Defeat Depression 